\title{
Kinetic Spectrophotometric Determination of Isoxsuprine in Dosage Forms Through Derivatisation with 4-Chloro-7- nitrobenzo-2-oxa-1,3-diazole (NBD-Cl)
}

\author{
N. El-Enany*, F. Belal and M. Rizk \\ Department of Analytical Chemistry, Faculty of Pharmacy, \\ University of Mansoura, 35516, Mansoura, Egypt.
}

\begin{abstract}
A simple and sensitive kinetic spectrophotometric method was developed for the determination of isoxsuprine in pharmaceutical preparations. The method is based upon a kinetic investigation of the coupling reaction between isoxsuprine $\mathrm{HCl}$ and 4-chloro-7-nitrobenzo-2-oxa-1,3-diazole (NBD-Cl) in borate buffer of $\mathrm{pH} 7.8$ for a fixed time of $30 \mathrm{~min}$. The absorbance of the yellow coloured product was measured at $395 \mathrm{~nm}$. The absorbance- concentration plot was rectilinear over the range of $2-20 \mu \mathrm{g} \mathrm{mL}^{-1}$ ( $\left.\mathrm{r}=0.9994\right)$ with minimum detectability of $0.6 \mu \mathrm{gL} \mathrm{m}^{-1}(1.75$ $\left.\times 10^{-6} \mathrm{M}\right)$. The different experimental parameters affecting the development and stability of the colour were carefully studied and optimized. The determination of isoxsuprine by the fixed-concentration and rate-constant methods is also feasible with the calibration equations obtained, but the fixed time method has been found to be more applicable. The proposed method was further applied to the determination of the drug in formulations. The results obtained were in good agreement with those obtained using a reference method. The reaction pathway was proposed.
\end{abstract}

\section{Keywords}

Kinetic determination, isoxsuprine $\mathrm{HCl}$, (NBD-Cl), pharmaceutical preparations. 


\section{Introduction}

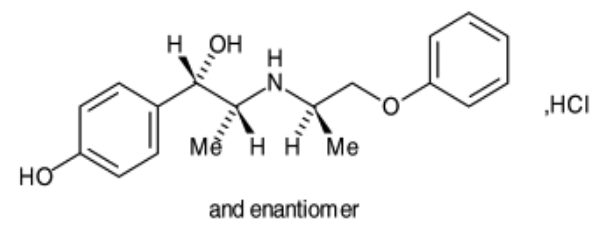

Scheme 1: Structural Formula of Isoxsuprine $\mathrm{HCl}$

Isoxsuprine (ISX), 4-Hydroxy- $\alpha$-[1-[(1-methyl-2-phenoxy-ethyl)amino]ethyl] benzenemethanol, is a vasodilator that produces the effects of $\beta$-adrenoceptor stimulation and $\alpha$-adrenoceptor antagonism; the former effect is the more predominant. It is used in the treatment of cerebral and peripheral vascular diseases. It is also used to arrest premature labor [1].

Several analytical methods have been reported for the determination of ISX in raw material, dosage forms and biological fluids. A good guide to the reported methods of this drug published up to 1997 is found in the comprehensive review written by Belal et al [2]. The more recent publications include spectrophotometry [3-6], polarography [7], HPLC [8,9]and LC-MS [10]. All these methods are either insufficiently sensitive [4,5] or tedious and require highly sophisticated and dedicated instrumentation [7-10]. This led us to study the reaction of ISX with 4chloro-7-nitrobenzo-2-oxa-1,3-diazole (NBD-Cl) to develop simple and sensitive spectrophotometric method for the determination of ISX in pharmaceutical preparations. ISX contains a secondary aliphatic amino group which is suitable for derivatization with chromogenic reagents such as NBD-Cl. The latter is a useful derivatizing agent for primary and secondary amines, thiol, etc. Several pharmaceutical compounds have been determined through this approach [11-16].

The literature is still poor in analytical procedures based on kinetics, especially for pharmaceuticals and biological fluids. However, some specific advantages in the application of kinetic methods can be expected such as: selectivity due to the measurement of the evolution of the absorbance with the time of the reaction instead of the measure of a concrete absorbance value [17]. Some pharmaceutical 
compounds were determined through kinetic approach [18-20]. ISX was determined kinetically before through oxidation with alkaline potassium permanganate [20], however this method is not specific since $\mathrm{KMnO}_{4}$ can oxidize both of ISX and its degradation products such as 4-hydroxybenzaldehyde, phydroxyacetophenone, 4-hydroxybenzylalcohol, and p-hydroxy benzoic acid. On the other hand the proposed method proved be specific for determination of ISX in the presence of its degradation products, and so could be considered as stability indicating method.

\section{Experimental}

\section{Reagents and Materials}

All chemicals used were of Analytical Reagent Grade. ISX $\mathrm{HCl}$ pure sample (Batch \# 191401) was purchased from Sigma, (Saint Louis, MO, USA). Tablets containing the drug: Duvadilan tablets (product of Pharco Pharmaceuticals. Alexandria, Egypt, Batch \# 198) labled to contain $20 \mathrm{mg}$ each and Vascular tablets (product of South Egypt Drug Industries Co. 6 October City, A.R.E.,

Batch \# 798140) labeled to contain $20 \mathrm{mg}$ each were obtained from commercial sources in the local market.

-4-Chloro-7-nitrobenzo-2-oxa-1,3-diazole (NBD-Cl) was purchased from Sigma ( St. louis USA). A stock solution containing $1 \mathrm{mg} \cdot \mathrm{mL}^{-1}$ was freshly prepared in methanol.

- Borate buffer (0.2 M, pH 7.8).

- Methanol, AR grade ( Aldrich, USA)

- $\mathrm{HCl}$ (Aldrich-Chemie, Germany).

Standard Solutions: A stock solution of ISX HCl was prepared by dissolving 20.0 $\mathrm{mg}$ of ISX HCl in $100 \mathrm{~mL}$ of distilled water and was further diluted with the same solvent as appropriate. The standard solutions were stable for seven days when kept in the refrigerator. 


\section{Apparatus}

UV- VIS 1601, Shimadzu recording Spectrophotometer (P/ N 206-67001) equipped with kinetic accessory and provided with temperature controlled cell (TCC-240A). Recording range from 0 to 1.0 absorbance unit, wavelength $(\mathrm{nm}) 395$, factor $=1$, number of cells 1 , reaction time $30 \mathrm{~min}$.

\section{Procedures}

\section{Recommended Procedure}

Transfer aliquots of ISX working standard solution into a series of $10 \mathrm{ml}$ volumetric flasks so that the final concentration is in the range of $2-20 \mu \mathrm{gL}^{-1}$. Add $5 \mathrm{~mL}$ of borate buffer ( $\mathrm{pH} 7.8$ ), then add $1.1 \pm 0.1 \mathrm{~mL}$ of $0.1 \% \mathrm{NBD}-\mathrm{Cl}$ and mix well. Heat at $60{ }^{\circ} \mathrm{C} \pm 2{ }^{\circ} \mathrm{C}$ for $30 \pm 2 \mathrm{~min}$ in a thermostatically-controlled water bath, then cool. Add $0.2 \mathrm{~mL}$ of $\mathrm{HCl}$. Complete to the mark with distilled water. Measure the absorbance of the solution at $395 \mathrm{~nm}$ against a reagent blank. Plot the measured absorbance vs the final concentration to get the calibration curve. Alternatively, derive the corresponding regression equation.

\section{Analysis of Commercial Tablets}

Weigh and pulverize twenty tablets. Transfer a weighed quantity of the powder equivalent to $20 \mathrm{mg}$ of ISX HCl into a small conical flask, extract with $3 \times 30 \mathrm{~mL}$ of distilled water. Filter the extract into $100 \mathrm{~mL}$ volumetric flask. Wash the conical flask with few $\mathrm{mLs}$ of distilled water. Pass the washings into the same volumetric flask and complete to the mark with the same solvent. Transfer aliquots covering the working concentration range into $10 \mathrm{~mL}$ volumetric flasks. Proceed as described under Recommended Procedure. Determine the nominal content of the tablets either from the calibration curve or using the corresponding regression equation. 


\section{Results and Discussion}

4-chloro-7-nitrobenzo-2-oxa-1,3-diazole (NBD-Cl), as an electroactive halide reagent, was first introduced as an analytical reagent for the determination of some amines and amino acids [11]. In recent reports. NBD-Cl was further used as a chromogenic reagent for the determination of some primary and secondary amines [12-16]. In the present study, ISX was found to react with NBD-Cl in borate buffer of $\mathrm{pH} 7.8$ producing a yellow color with maximum absorbance at $395 \mathrm{~nm}$. (Fig. 1).

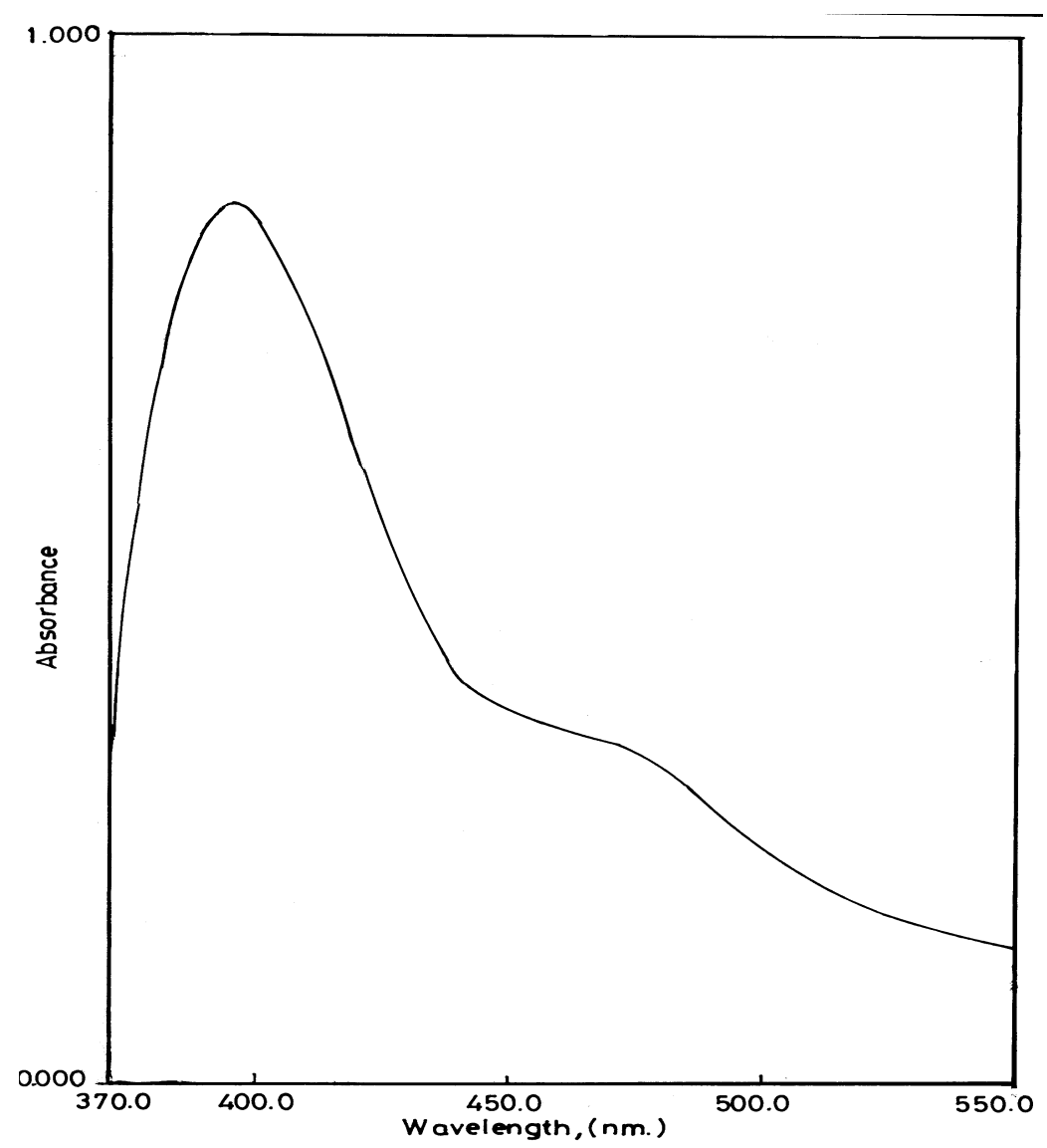

Fig. 1. Absorption spectrum of the reaction product of isoxsuprine $\mathrm{HCl}$ $\left(20 \mu \mathrm{gL}^{-1}\right)$ with NBD-Cl at $\mathrm{pH} 7.8$. 


\section{Study of experimental conditions}

The spectrophotometric properties of the colored product as well as the different experimental parameters affecting the color development and its stability were carefully studied and optimized. Such factors were changed individually while the others were kept constant. The factors include $\mathrm{pH}$, type of buffer, temperature, time of heating, effect of sensitizers and surfactants.

The influence of $\mathrm{pH}$ on the absorbance value of the reaction product was evaluated. Maximum absorbance value was obtained at $\mathrm{pH} 7.8$ after which the absorbance of the reaction product began to decrease gradually until $\mathrm{pH} 9.5$. Therefore, $\mathrm{pH}$ of 7.8 was chosen as the optimum pH (Fig. 2). Other buffers having the same $\mathrm{pH}$ value such as phosphate buffer and hexamine buffer were tried and compared with $0.2 \mathrm{M}$ borate buffer. The borate buffer was found to be superior to the phosphate and hexamine buffers having the same $\mathrm{pH}$ value since it gave the highest absorbance value. This is probably, because the rate of hydrolysis of NBD$\mathrm{Cl}$ to NBD-OH was much slower. This result is in agreement with that of Miyano et al. [21].

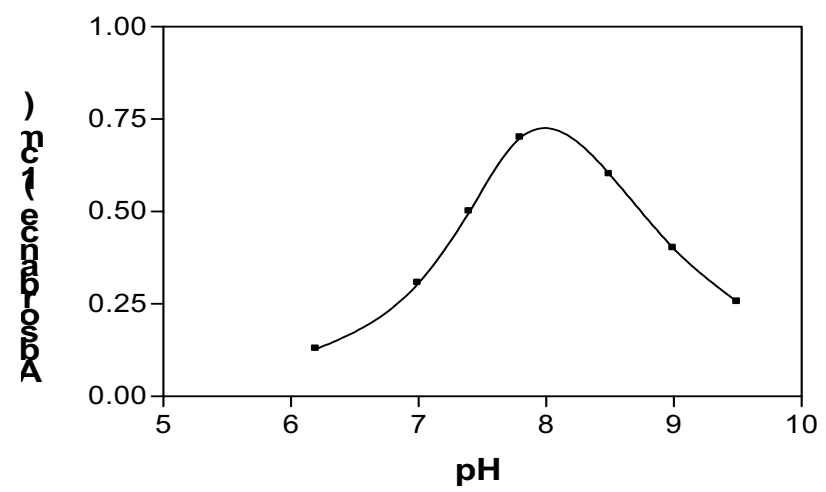

Fig. 2. Effect of $\mathrm{pH}$ on the absorbance value of the reaction product of isoxuprine $\mathrm{HCl}(16 \mu \mathrm{g} \mathrm{mL}-1)$ with NBD-Cl

The influence of the concentration of NBD-Cl was studied using different volumes of $0.1 \%$ solution of the reagent. It was found that, the reaction of NBD-Cl 
with ISX started upon using $0.2 \mathrm{~mL}$ of the reagent in the presence of borate buffer of $\mathrm{pH}$ 7.8. Increasing the volume of the reagent, produces a proportional increase in the absorbance of the reaction product up to $1 \mathrm{~mL}$ and remains constant till $1.2 \mathrm{~mL}$, after which further increase produces a gradual decrease in the absorbance value. Therefore, $1.1 \pm 0.1 \mathrm{~mL}$ of $0.1 \%$ of NBD-Cl solution was chosen as the optimal volume of the reagent (Fig. 3).

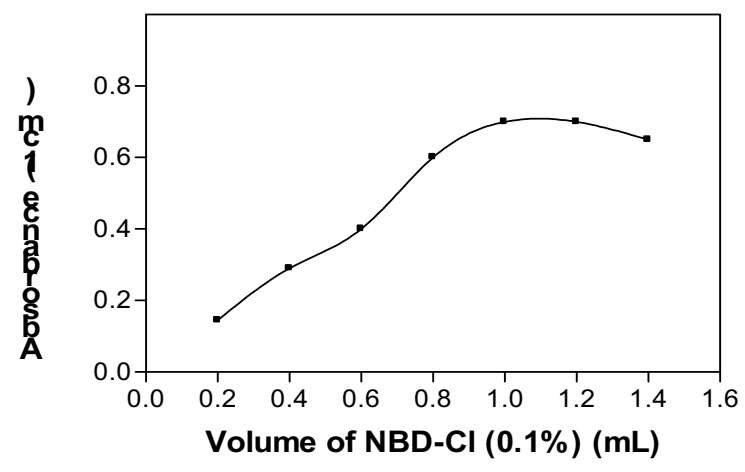

Fig. 3. Effect of volume of NBD-Cl $(0.1 \%)$ on the absorbance value of the reaction product of isoxuprine $\mathrm{HCl}$ (16 $\mathrm{mg} \mathrm{mL}^{-1}$ ) at $\mathrm{pH} 7.8$.

Different temperature settings were used with constant heating time. Increasing the temperature was found to produce a proportional increase in the absorbance of the reaction product up to boiling. It was found that heating at a relatively lower temperature $\left(60^{\circ} \mathrm{C}\right)$ for longer period $(30 \mathrm{~min})$ was better than heating at a higher temperature for a shorter period of time, regarding the reproducibility of the absorbance.

The time of heating is an essential part of the experiment.

Different time intervals were tested to ascertain the time after which the solution attained its highest absorbance value. It was found that after $30 \mathrm{~min}$, the reaction product reached the highest absorbance value (Fig. 4). It was observed that heating time for $30 \mathrm{~min}$ is adequate and the absorbance value of the reaction product is stable for about $40 \mathrm{~min}$. at room temperature. 


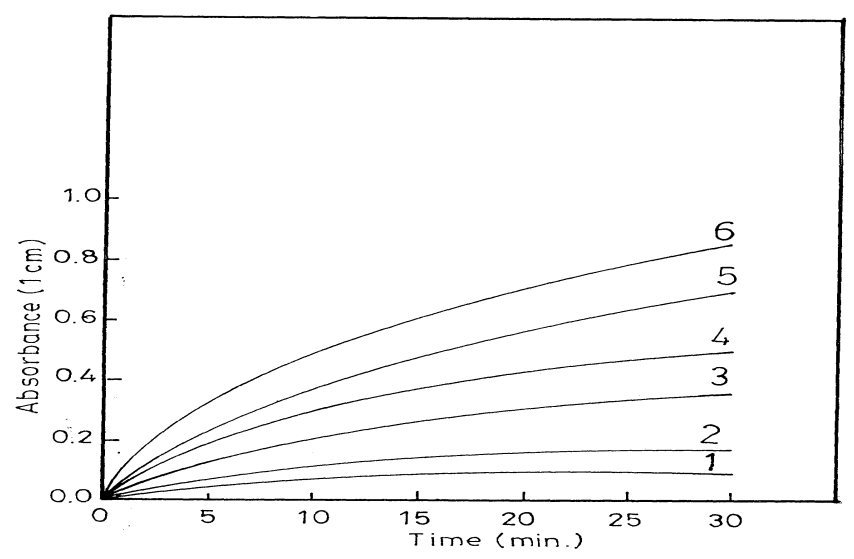

Fig. 4 . Effect of time on the absorbance of isoxsuprine $\mathrm{HCl}$

(1) $5.920 \times 10^{-6} \mathrm{M}$

( 2 ) $1.184 \times 10^{-5} \mathrm{M}$

( 3 ) $2.368 \times 10^{-5} \mathrm{M}$

( 4 ) $3.552 \times 10^{-5} \mathrm{M}$

( 5 ) $4.736 \times 10^{-5} \mathrm{M}$

( 6 ) $5.920 \times 10^{-5} \mathrm{M}$.

Acidification of the reaction mixture prior to measurement of the absorbance Value remarkadly decreased the background absorbance due to the formation of NBD-OH without affecting the drug-reagent adduct, hence the sensitivity was increased. Therefore, the absorbance of the hydrolysis product of NBD-Cl, namely, 4-hydroxy-7-nitrobenzo-2-oxa-1,3-diazole (NBD-OH) is quenched by decreasing the $\mathrm{pH}$ of the reaction medium to less than 1.

Preliminary attempts had been carried out to enhance the quantum yeild by the addition of some sensitizers and surfactants, Different sensitizers such as quinine, fluorescein and rhodamine-B, at concentrations of $5 \mu \mathrm{g} \mathrm{mL}^{-1}$ were tested by adding tothe reactants mixture before heating. Outstanding inhibitory effects were observed (Tab. 1) as these sensitizers reacted with NBD-Cl. 
In the same manner, the effect of surfactants on the color development was studied. Different sufactants (cetrimide, gelatine and sodium lauryl sulphate) at three different concentrations $2.5,7.5$ and $15 \mathrm{\mu g} \mathrm{mL}^{-1}$, were tested by adding to the reaction mixture prior to heating. All tested surfactants reacted with NBD-Cl producing an inhibitory effect, as evident from low absorbance reading. The results obtained are given in Table 1.

\begin{tabular}{|l|c|c|}
\hline \multicolumn{1}{|c|}{ Surfactant } & $\begin{array}{c}\text { Concentration } \\
\left(\mu \mathrm{g} \mathrm{m}^{-1}\right)\end{array}$ & Absorbance \\
\hline No surfactant & 0 & 0.420 \\
Cetrimide & 2.5 & 0.430 \\
Sodium lauryl sulfate & 2.5 & 0.247 \\
Gelatin & 2.5 & 0.333 \\
Cetrimide & 7.5 & 0.214 \\
Sodium lauryl sulfate & 7.5 & 0.314 \\
Gelatin & 7.5 & 0.297 \\
Cetrimide & 15 & 0.230 \\
Sodium lauryl sulfate & 15 & 0.300 \\
Gelatine & 15 & 0.316 \\
No sensitizer & 0 & 0.420 \\
Quinine & 5 & 0.292 \\
Fluorescein & 5 & 0.421 \\
Rhodamine-B & 5 & 0.390 \\
\hline
\end{tabular}

Tab 1: Effect of surfactants and sensitizers on the performance of the proposed method after heating at $60^{\circ} \mathrm{C}$ for $30 \mathrm{~min}$

\section{Analytical Performance}

The rate of the reaction was found to be concentration-dependent. The rate of the reaction was followed at $60{ }^{\circ} \mathrm{C}$ with various concentrations of the drug in the 
range of 2-20 $\mu \mathrm{g} \mathrm{mL}^{-1}$, keeping NBD-Cl and borate buffer concentrations constant (Fig. 5).

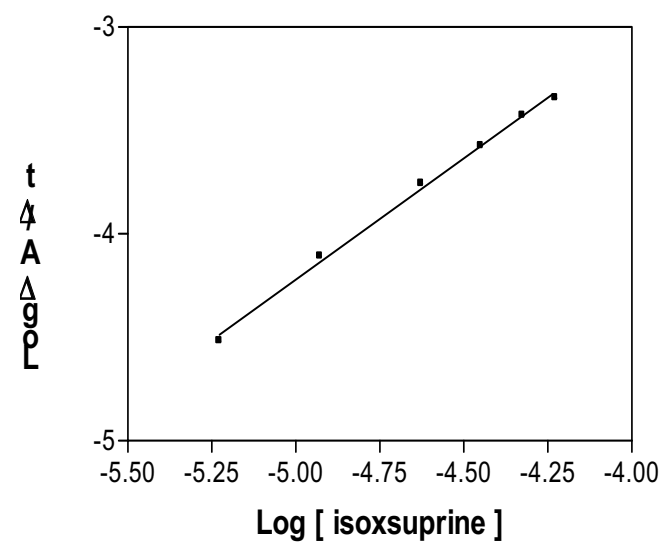

Fig. 5. plot of $\log \Delta \mathrm{A} \Delta \mathrm{t}$ (reaction rate ) versus log [isoxsuprine]

The reaction rate was found to obey the following equation:

Rate $=\mathrm{K}^{`}[\mathrm{ISX} . \mathrm{HCl}]^{\mathrm{n}}$

where $k$ is the pseudo-order rate constant and $n$ is the order of the reaction.

The rate of the reaction may be estimated by the variable-time method [22] as $\Delta \mathrm{A} / \Delta \mathrm{t}$, where $\mathrm{A}$ is the absorbance and $\mathrm{t}$ is the time in seconds. Taking logarithms of rates and concentrations (Table 2) equation (1) is transformed into:

$\log ($ rate $)=\log \Delta \mathrm{A} / \Delta \mathrm{t}=\log \mathrm{K}^{\prime}+\mathrm{n} \log [\mathrm{ISX} . \mathrm{HCl}]$

Regression of log (rate) versus log [ISX. HCl] gave the regression equation;

Log rate $=1.638+1.172 \log C$

$(r=0.9984)$

Hence $K^{`}=43.45 \mathrm{Sec}^{-1}$ and the reaction is first order $\quad(n=1.17)$ with respect to isoxsuprine concentration. 


\begin{tabular}{|l|l|}
\hline $\log \Delta \mathrm{A} / \Delta \mathrm{t}$ & Log $[\mathrm{ISX} . \mathrm{HCl}]$ \\
\hline-4.519 & -5.227 \\
-4.109 & -4.927 \\
-3.757 & -4.626 \\
-3.575 & -4.449 \\
-3.429 & -4.325 \\
-3.344 & -4.227 \\
\hline
\end{tabular}

Tab. 2. Logarithms of rates for different concentrations at room temperature at $395 \mathrm{~nm}$.

\section{Evaluation of the kinetic methods:}

The quantitation of ISX. $\mathrm{HCl}$ under the optimized experimental conditions outlined above, would result in a pseudo-first order with respect to its concentrations. However, the rate will be directly proportional to isoxsuprine concentration resulting in a pseudo-first order rate equation as follows:

$$
\text { Rate }=K^{\prime}[\text { ISX. } \mathrm{HCl}]
$$

where $K^{`}$ is the pseudo-first order rate constant. Several experiments were then carried out to obtain isoxsuprine concentration from the rate data according to equation ( 3 ).

Initial rate, rate constant, fixed concentration and fixed time methods [23-24] were attempted and the most suitable analytical method was selected taking into account the applicability, the sensitivity, the intercept and the correlation coefficient $(r)$.

\section{The Rate constant method:}

Graphs of log absorbance versus time for ISX. $\mathrm{HCl}$ concentration in the range of $1.184 \times 10^{-5}$ to $5.920 \times 10^{-5} \mathrm{M}$ were plotted and all appeared to be 
rectilinear. Pseudo-first order rate constant $\left(\mathrm{K}^{\prime}\right)$ corresponding to different ISX. $\mathrm{HCl}$ concentrations $(C)$ were calculated from the slopes multiplied by -2.303 and are presented in Table 3. Regression of $(C)$ versus $K^{\prime}$ gave the following equation:

\begin{tabular}{|l|l|}
\hline $\mathrm{K}\left(\mathrm{S}^{-1}\right)$ & {$[\mathrm{ISX} . \mathrm{HCl}]$} \\
\hline $3.455 \times 10^{-4}$ & $1.184 \times 10^{-5} \mathrm{M}$ \\
$2.879 \times 10^{-4}$ & $2.368 \times 10^{-5} \mathrm{M}$ \\
$2.303 \times 10^{-4}$ & $3.552 \times 10^{-5} \mathrm{M}$ \\
$1.974 \times 10^{-4}$ & $4.736 \times 10^{-5} \mathrm{M}$ \\
$1.727 \times 10^{-4}$ & $5.920 \times 10^{-5} \mathrm{M}$ \\
\hline
\end{tabular}

Tab. 3. Values of $K^{\prime}$ calculated from slopes of $\log A$ versus $t$ graphs at $395 \mathrm{~nm}$.

\section{The Fixed concentration method:}

Reaction rates were recorded for different ISX. $\mathrm{HCl}$ concentrations in the range of $2.368 \times 10^{-5}-5.920 \times 10^{-5} \mathrm{M}$. A preselected value of the absorbance (0.3) was fixed and the time was measured in seconds. The reciprocal of time (1/t) versus the initial concentration of ISX. $\mathrm{HCl}$ (Table 4) was plotted and the following equation of the calibration graph was obtained:

$$
1 / t=-7.456 \times 10^{-4}+67.465 C \quad(r=0.9843)
$$




\begin{tabular}{|l|l|}
\hline $1 / \mathrm{t}\left(\mathrm{S}^{-1}\right)$ & {$[\mathrm{ISX} . \mathrm{HCl}]$} \\
\hline $7.937 \times 10^{-4}$ & $2.368 \times 10^{-5} \mathrm{M}$ \\
$1.852 \times 10^{-3}$ & $3.552 \times 10^{-5} \mathrm{M}$ \\
$2.222 \times 10^{-3}$ & $4.736 \times 10^{-5} \mathrm{M}$ \\
$3.333 \times 10^{-3}$ & $5.920 \times 10^{-5} \mathrm{M}$ \\
\hline
\end{tabular}

Tab. 4. Values of reciprocal of time taken at fixed absorbance for different rates of variable concentrations of ISX. $\mathrm{HCl}$ at constant concentrations of NBD-Cl and borate buffer.

\section{The Fixed-time method:}

Reaction rates were determined for different concentrations of ISX. $\mathrm{HCl}$. At a pre -selected fixed-time, which was accurately determined, the absorbance was measured. Calibration graphs of absorbance versus initial concentration of ISX. $\mathrm{HCl}$ were established at fixed times of $5,10,15,20$ and $30 \mathrm{~min}$. with regression equations assembled in Tab. 5.

\begin{tabular}{|l|l|l|}
\hline Time (min.) & Regression equation & $\begin{array}{l}\text { Correlation } \\
\text { Coefficient }(r)\end{array}$ \\
\hline 5 & $A=5.096 \times 10^{-3}+0.015 \mathrm{C}$ & $r=0.9948$ \\
10 & $\mathrm{~A}=1.848 \times 10^{-3}+0.027 \mathrm{C}$ & $\mathrm{r}=0.9985$ \\
15 & $\mathrm{~A}=2.792 \times 10^{-3}+0.032 \mathrm{C}$ & $\mathrm{r}=0.9972$ \\
20 & $\mathrm{~A}=-7.826 \times 10^{-3}+0.036 \mathrm{C}$ & $\mathrm{r}=0.9993$ \\
30 & $\mathrm{~A}=1.562 \times 10^{-4}+0.043 \mathrm{C}$ & $\mathrm{r}=0.9994$ \\
\hline
\end{tabular}

Tab. 5. Regression equation for ISX. $\mathrm{HCl}$ at different fixed time over the range $5.920 \times 10^{-6}$ to $5.920 \times 10^{-5} \mathrm{M}$ at $395 \mathrm{~nm}$. 
It is clear that, the slope increases with time and the most acceptable values of the correlation coefficient $(r)$ and the intercept were obtained for a fixed time of $30 \mathrm{~min}$, which was therefore chosen as the most suitable time interval for measurement.

After optimizing the reaction conditions, the fixed time method was applied to the determination of isoxsuprine in pure form over the range of $2-20 \mu \mathrm{g} \mathrm{m}^{-1}$. Analysis of the data gave the following equations:

$A=1.562 \times 10^{-4}+0.043 C$

$$
(r=0.9994)
$$

where $A$ is the absorbance at $395 \mathrm{~nm}$.

and $C$ is the concentration in $\mu \mathrm{g} \mathrm{mL}^{-1}$.

The limit of quantification (LOQ) was determined by establishing the lowest concentration that can be measured with acceptable accuracy and precision and was found to be $2 \mu \mathrm{gL}^{-1}$.

The limit of detection (LOD) was determined by establishing the minimum level at which the analyte can be reliably detected and was found to be $0.6 \mu \mathrm{g} \mathrm{mL}^{-1}$ $\left(1.75 \times 10^{-6} \mathrm{M}\right)$.

\section{Validation of the method}

The method was tested for linearity, specificity, precision and reproducibility.

\section{Linearity:}

By using the above spectrophotometric procedures, linear regression equations were obtained. The regression plots showed that there was a linear dependence of the absorbance value on the concentration of the drug over the range of $2-20 \mu \mathrm{g} \mathrm{mL}^{-1}$. The validity of the method was evaluated by Statistical evaluation of the regression lines. It was found that the standard deviation of the residuals $\left(S_{y / x}\right)$ is $8.471 \times 10^{-3}$, the standard deviation of the intercept $\left(S_{a}\right)$ is $5.024 \mathrm{x}$ $10^{-3}$ and standard deviation of the slope $\left(S_{b}\right)$ is $5.430 \times 10^{-4}$. The small values of the 
figures point out to the high precision of the proposed method and low scattering of the points of the calibration curve and high accuracy.

The proposed method was applied to the assay of a pure sample of ISX. $\mathrm{HCl}$. The results obtained by the proposed method were compared with those given by a reference method [25]. Statistical analysis [26] of the results obtained by both methods using Student's t- test and variance ratio, F- test, reveals no significant difference in the performance of the two methods, regarding the accuracy and precission, respectivily (Tab.6).

\section{Precision and Repeatability:}

The within days precision was evaluated through replicate analysis of sample spiked with $16 \mu \mathrm{g} \mathrm{mL}$. The percentage recoveries based on four separate determinations ranged from 98.90 to 99.88 with mean percentage recovery of 98.96 \pm 0.88 , thus indicating the high precision of the method.

The inter-day precision on four successive days was evaluated through replicate analysis of sample spiked with $16 \mu \mathrm{g} \mathrm{mL}^{-1}$. The percentage recoveries based on the average of four separate determinations were $98.92 \pm 0.93$.

\section{Specificity of the proposed method}

The major degradation products of ISX. $\mathrm{HCl}$ are: 4-hydroxybenzaldehyde, $\mathrm{p}$ hydroxyacetophenone, 4-hydroxybenzyl alcohol, and p-hydroxybenzoic acid [27] did not interfere with the determination of ISX by the proposed method, since the main reaction depends on the presence of secondary aliphatic amine. So, the proposed method proved to be specific for intact molecule in the presence of its degradation products. Hence the proposed method can be considered as stability indicating assay for the determination of ISX in the presence of its degradation products. Additive excipients commonly incorporated in tablet formulations did not interfere with the proposed method as experimentally checked (Tab. 6). 


\section{Pharmaceutical applications}

The proposed method was further applied to the determination of ISX in its tablets dosage form. Common tablets excipients such as talc, lactose, starch, avisil, gelatine and magnesium stearate did not interfere with the assay. The results obtained were compared with those given using a reference method [25]. Statistical analysis [26] of the results using Student's t-test and variance ratio Ftest, revealed no significant difference between the two methods at the $95 \%$ confidence level regarding accuracy and precision, respectively. The results obtained are abridged in Tab. 6.

\section{Mechanism of the reaction}

The stoichiometry of the reaction was studied adopting the limiting logarithmic method [28]. The absorbance of the reaction product was alternatively measured in the presence of excess of NBD-Cl and ISX. A plot of log absorbance versus log [NBD-Cl] and log [ISX] gave straight lines, the values of the slopes are 0.980 and 1.006 respectively (Fig. 6). Hence, it is concluded that, the molar reactivity of the reaction is $0.980 / 1.006$,i.e. the reaction proceeds in the ratio of $1: 1$, confirming that one molecule of the drug denses with one molecule of NBD-Cl. The drug reacts via the secondary amino group with the chlorine atom of the reagent with the liberation of hydrochloric acid. Based on the obtained molar reactivity, the reaction pathway is proposed to proceed as follows:

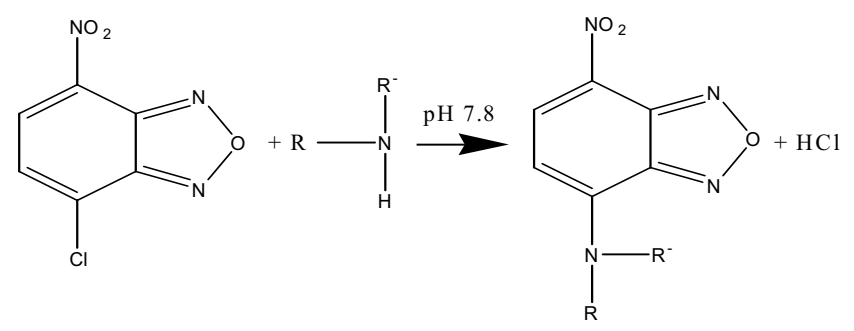

Scheme 2: Proposal reaction pathway between NBD-Cl and ISX 

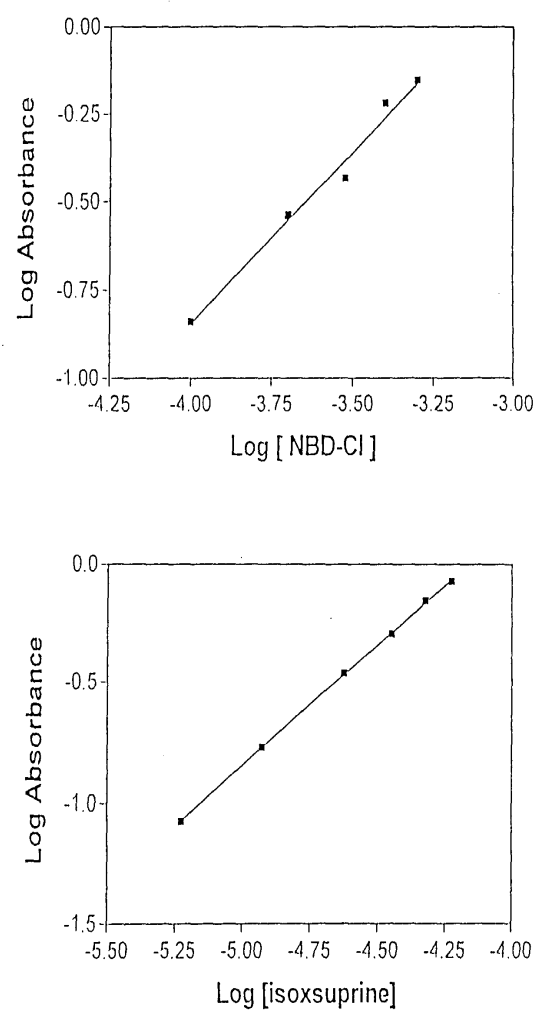

Fig. 6 . Limiting logarithmic plots for the molar ratio.
(A) Log A vs. Log [NBD-Cl]
(B) Log A vs. log [isoxsuprine]

\section{Conclusion}

Different methods were established to determine isoxsuprine concentration kinetically, the reaction rate method, rate constant and fixed time methods were applied. Applying the fixed time method, it is clear that the slope increased with time and the most acceptable values of correlation coefficients $(r)$ and intercepts were obtained for a fixed time of $30 \mathrm{~min}$. which was therefore chosen as the most suitable time interval for measurements. The proposed method is selective for the determination of the drug in the presence of its degradation products. 


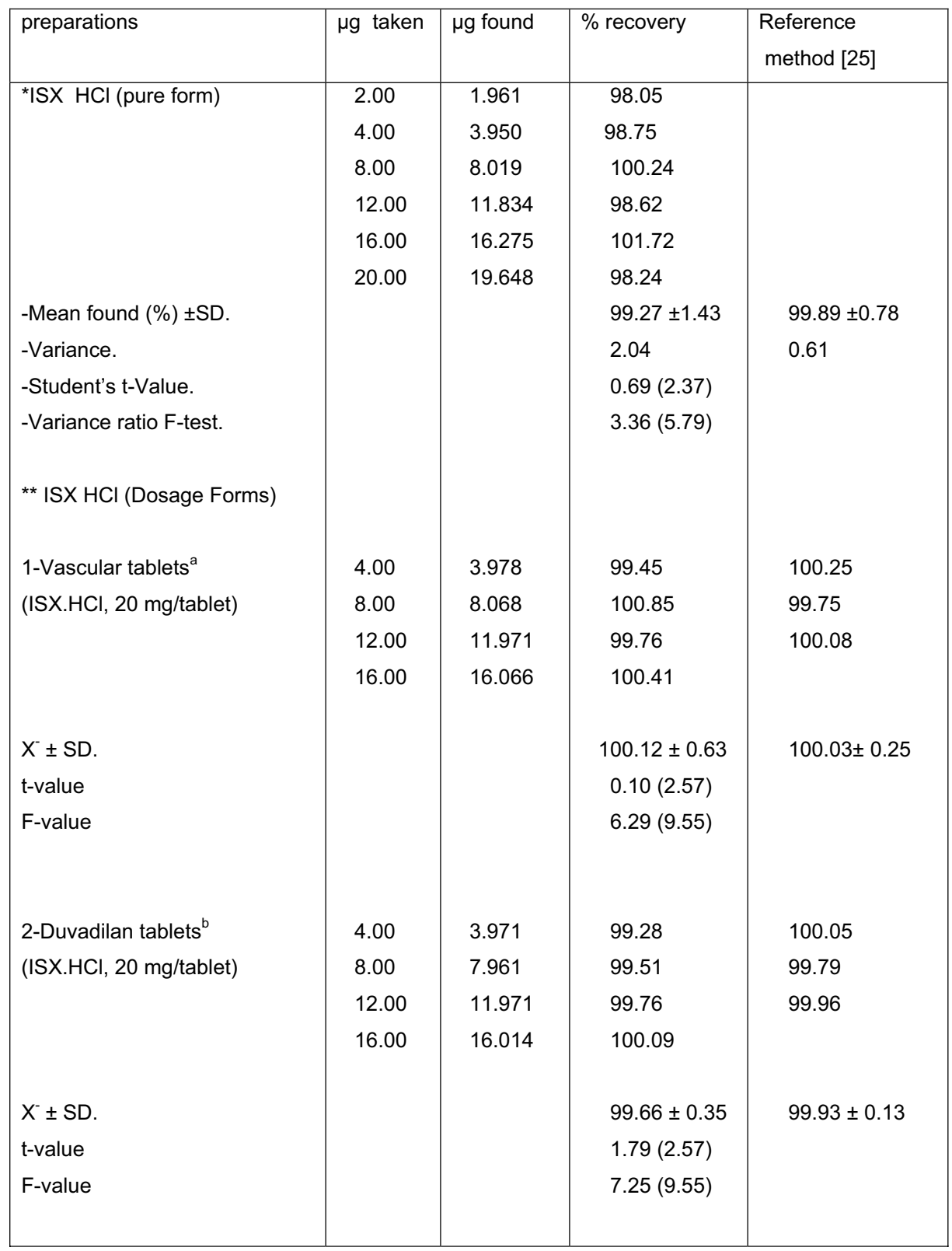

Tab. 6. Application of the proposed method to the determination of

ISX $\mathrm{HCl}$ in in pure form and dosage forms using fixed time method.

N.B.:

Figure in parentheses are the tabulated values of $\mathrm{t}$ and $\mathrm{F}$ respectively at $\mathrm{p}=0.05$ [26]

${ }^{a}$ is product of South Egypt Drug Industries Co. 6 October City, A.R.E.

${ }^{\mathrm{b}}$ is product of Pharco Pharmaceuticals. Alexandria, Egypt. 


\section{References:}

[1] Reynolds J.E.F., " in Martindale, The Extra Pharmacopoeia”, $31^{\text {st }}$ Ed., The Pharmaceutical Press, London 1996, p. 1577,1580.

[2] Belal F., Al-Badr A.A., Al-Majed A.A. and El-Subbagh H.I., in Analytical Profile of Drug Substances and Excepients, Vol. 26, Brittain, G.H., editor, Academic Press, New York 1999, p. 359-393.

[3] Reddy M.N., Sankar D.G. and Rao K.V. P. Spectrophotometric determination of isoxsuprine and nyldrine using 1,10 phenanthroline. Indian Drugs. 1998; 35: 163.

[4] Demir C., Brereton R. G. Mutivariante calibration on designed mixtures of pharmaceuticals. Analyst. 1998; 123: 181-189.

[5] Daabees H. G. Spectrophotometric determination of isoxsuprine hydrochloride Alex. J. Pharm. Sci. 2001;15: 25-29.

[6] Beyene N. W., VanStaden J. F., Stefan R. I., Aboul-Enein H. Y. Determination of isoxsuprine hydrochloride by sequential injection visible spectrophotometry II Farmaco. 2005; 60: 613-619.

[7] Belal F., Al-Malaq H. A. and Al-Majed A.A. Voltammetric determination of isoxsuprine and fenoterol in dosage forms and biological fluids through nitrosation J. Pharm. Biomed. Anal. 2000; 23: 1005-1015.

[8] Belal F., Al-Malaq H.A., Al-Majed A. A., Gadkariem E. A. A stability indicating HPLC method for the determination of isoxsuprine in dosage forms; application to kinetic studies of isoxsuprine. J. Liq. Chromatogr. : Rel. Technol. 2000; 23: 3175-3189.

[9] Brambilla G., Fiori M., Curiel I., Serpe L., Gallo P. a1 -Acid glycoprotein affinity columns for the clean-up of adrenergic drugs. Analyst. 1998; 123: 2693-2696.

[10] Kootsra, P. R., Kuijpers C.J.P.F., Wubs K.L. Van Doorn D., Strek S.S., Van Ginkel L. A., Stephany R. W.

The analysis of beta-agonists in bovine muscle using molecular imprinted polymers with ion trap LCMS screening. Anal. Chim. Acta. 2005; 529: 75-81.

[11] Saleh H. M. and Al-Ghannam Sh. M.

Colourimetric determination of aromatic amino acids.

Alex. J. Pharm. Sci. 2000; 14: 25-29.

[12] El-Enany N.

Spectroflurimetric and spectrophotometric determination of gliclazide in pharmaceuticals by derivatization with 4-chloro-7-nitrobenzo-2-oxa-1,3 diazole J.Assoc.Off.Anal.Chem.International.2003; 86: 209-214. 
[13] El-Enany N., Belal F., Rizk M.

Spectrophotometric determination of salbutamol in bulk and dosage forms after derivatization with 4-chloro-7-nitrobenzo-2-oxa-1,3-diazole (NBD-Cl). Chem. Anal. 2004; 49: 1-9.

[14] Al-Majed A.A., Belal F., Abounassif M.A., Khalil N.Y.

Fluorimetric determination of Gentamicin in dosage forms and biological fluids through derivatization with 4-chloro-7-nitrobenzo-2-oxa-1,3diazole (NBD-Cl). Microchim. Acta. 2003; 141: 1-6.

[15] El-Shabrawy Y., Belal F., Sharf El-Din M., Shalan Sh. Spectrophotometric determination of fenoterol hydrobromide in pure and dosage forms.

IL Farmaco. 2003; 58: 1033-1038.

[16] Hassan E.M., Belal F., Al-Deeb O.A. and Khalil N.Y. Spectrofluorimetric determination of vigabatrin and gabapentin in dosage forms and spiked plasma sample through derivatization with 4-chloro-7nitrobenzo-2-oxa-1,3-diazole (NBD-Cl)

J. Assoc. Off. Anal. Chem. International.2001; 84: 1017-1024.

[17] Espinosa-Mansilla A., Acedovalenzuela M.I., Salinas F. and Canada F. Kinetic determination of ansamicins in pharmaceutical formulations.

Anal. Chim. Acta. 1998; 376: 365-375.

[18] Rizk M., Belal F., Ibrahim F., Ahmed S. and El-Enany N.

A simple kinetic spectrophotometric method for the determination of certain quinolones in drug formulations.

Sci. Pharm. 2000; 68: 173-188.

[19] Rizk M., Belal F., Ibrahim F., Ahmed S. and El-Enany N.

A simple kinetic spectrophotometric determination of oxamniquine in formulations and spiked biological fluids.

J. Pharm. Biomed. Anal. 2000; 23: 503-513.

[20] El-Enany N., Belal F and Rizk M.

A simple kinetic spectrophotometric method for the determination of isoxuprine in dosage forms.

IL Farmaco .2002; 57: 641-648.

[21] Miyano, H., Toyo'oka T. and Imai, K.

Anal. Chim. Acta. 1985; 170: 81-87.

[22] Weisberger A., Friess S. L. and Lewis E. S. "Techniques of Organic Chemistry”, Vol.III, Part I, Interscience, New York (1953).

[23] Yatsimirskii, K.B., Kinetic Methods of Analysis", Pergamon Press, Oxford. (1966).

[24] Laitinen, H.A., Harris W.E., Chemical Analysis", 2nd ed., McGraw-Hill, New York (1975).

[25] Chatterjee P.K., Jain C. L., Sethi P.D. Colourimetric determination of isoxsuprine $\mathrm{HCl}$ through nitrosation and subsequent chelation Indian Drugs. 1987; 24: 210-213. 
[26] Miller J.C., Miller J.N., editors

Statistics for Analytical Chemists,

Ellis Horwood Chichester, 1984; 22:82

[27] Volpe F., Zintel J., Spiegel D.

High-performance liquid chromatographyof two peripheral vasodilators, nylidrin [buphenine] hydrochloride and isoxsuprine hydrochloride in pharmaceutical dosage forms

J. Pharm. Sci. 1979;68: 1264-1264.

[28] Rose, J, Advenced Physico-Chemical Experiments, Pitman, London 1964, p.67. 